\title{
Northwest Pacific subtropical countercurrent on isopycnal surface in summer
}

\author{
Peter C. Chu \\ Naval Ocean Analysis and Prediction Laboratory, Department of Oceanography, Naval Postgraduate School, Monterey, CA, \\ USA
}

\author{
Rongfeng Li and Xiaobao You \\ LASG, Institute of Atmospheric Physics, Chinese Academy of Sciences, Beijing, China
}

Received 31 January 2002; accepted 7 May 2002; published 13 September 2002.

[1] A three-dimensional absolute velocity field on the isopycnal surface in the northwest Pacific subtropical region in the summer is calculated from the Navy's Generalized Digital Environmental Model (GDEM) climatological temperature and salinity data on a $0.5^{\circ} \times 0.5^{\circ}$ grid using the P-vector method. GDEM for the area was built from historical (1930-1997) temperature and salinity profiles. The basic current system, consisting of North Equatorial Current, Kuroshio and its recirculation, Subtropical Countercurrent (STCC), is identified. STCC occurs from the surface to the level of $\sigma_{\theta}=25.8$ between $18^{\circ} \mathrm{N}$ and $23.5^{\circ} \mathrm{N}$, with a maximum velocity around $0.1 \mathrm{~m} / \mathrm{s}$. At $\sigma_{\theta}=23.5, \mathrm{STCC}$ originates east of Luzon Strait at around $122.5^{\circ} \mathrm{E}$ and meanders eastward. As $\sigma_{\theta}$ increases, its origin shifts toward northeast. Comparison between velocity and potential vorticity fields leads to the conclusion that the STCC core is above the southern boundary of the subtropical mode water. INDEX TERMS: 4576 Oceanography: Physical: Western boundary currents; 4572 Oceanography: Physical: Upper ocean processes; 4520 Oceanography: Physical: Eddies and mesoscale processes; 4512 Oceanography: Physical: Currents; 4532 Oceanography: Physical: General circulation. Citation: Chu, P. C., R. Li, and X. You, Northwest Pacific subtropical countercurrent on isopycnal surface in summer, Geophys. Res. Lett., 29(17), 1842, doi:10.1029/2002GL014831, 2002.

\section{Introduction}

[2] One expects a westward flow in the subtropical northwest Pacific (Figure 1) feeding the western boundary current based on the classical wind-driven theory. However, early observations [e.g., Uda, 1955] show the occurrence of eastward flow segment north of $15^{\circ} \mathrm{N}$. Yoshida and Kidokoro $[1967 \mathrm{a}, 1967 \mathrm{~b}]$ predicted the existence of an eastward current in the subtropical region especially $20^{\circ}-25^{\circ} \mathrm{N}$ after computing the Sverdrup transport currents from the surface wind stress, and named it as the Subtropical Countercurrent (STCC). This current was subsequently confirmed by Uda and Hasunuma [1969] from direct current meter observations and geostrophic calculations, and by White et al. [1978] using historical expendable bathythermograph (XBT) data. Qiu [1999] inferred temporal and spatial variability of STCC using the altimeter data from the first $51 / 4$-yr TOPEX/POSEIDON mission, and found that the

Copyright 2002 by the American Geophysical Union. 0094-8276/02/2002GL014831\$05.00 eddy kinetic energy of STCC is maximum in April/May and minimum in December/January.

[3] Regardless the advancement of the knowledge on STCC, there is still lack of quantitative description of STCC such as its origin and spatial variability especially on the isopycnal surface. In this study, the P-vector method on the isopycnal surfaces [Chu, 1995, 2000; Chu and $\mathrm{Li}, 2000]$ is used to calculate the absolute velocity in the northwest Pacific $\left[15^{\circ}-35^{\circ} \mathrm{N}, 120^{\circ}-145^{\circ} \mathrm{E}\right]$ from the Navy's Generalized Digital Environmental Model (GDEM) climatological June temperature and salinity data set with $0.5^{\circ} \times 0.5^{\circ}$ resolution [Teague et al., 1990]. The P-vector method is a two-step inverse method with determination of the direction of the current (P-vector) at first and then the magnitude using the thermal wind relation. The two necessary conditions for validity of inversion are easily cooperated into the P-vector method. The rest of the paper is outlined as follows: Section 2 depicts the Navy's GDEM data set. Section 3 describes the computation in the isopycnal coordinate system. Section 4 depicts the June mean calculated absolute velocity fields. Section 5 presents the spatial variability of STCC in June. Section 6 discusses the connection of STCC and the potential vorticity (PV) field. Section 7 presents the conclusions.

\section{The Navy's GDEM}

[4] Data for building the current version of GDEM climatology were obtained from the Navy's Master Oceanographic Observational Data Set (MOODS), which has more than 5 million profiles during 1920-1998. The basic design concept of GDEM is the determination of a set of analytical curves that represent the mean vertical distributions of temperature and salinity for grid cells $\left(0.5^{\circ} \times 0.5^{\circ}\right)$ through the averaging of the coefficients for the curves found for individual profiles [Teague et al., 1990]. Different families of representative curves have been chosen for shallow, middepth, and deep-depth ranges, with each chosen so that the number of parameters required to yield a smooth, mean profile over the range was minimized. As pointed by Teague et al. [1990], large-scale oceanographic features are similarly represented in both GDEM and the NOAA Climatological Atlas of the World Ocean temperature and salinity.

\section{Isopycnal Coordinate System}

\subsection{Vertical Discretization}

[5] From the GDEM T, S data set, the potential density varies from 22.2 to 27.725 . We discretize $\sigma_{\theta}$ with the 


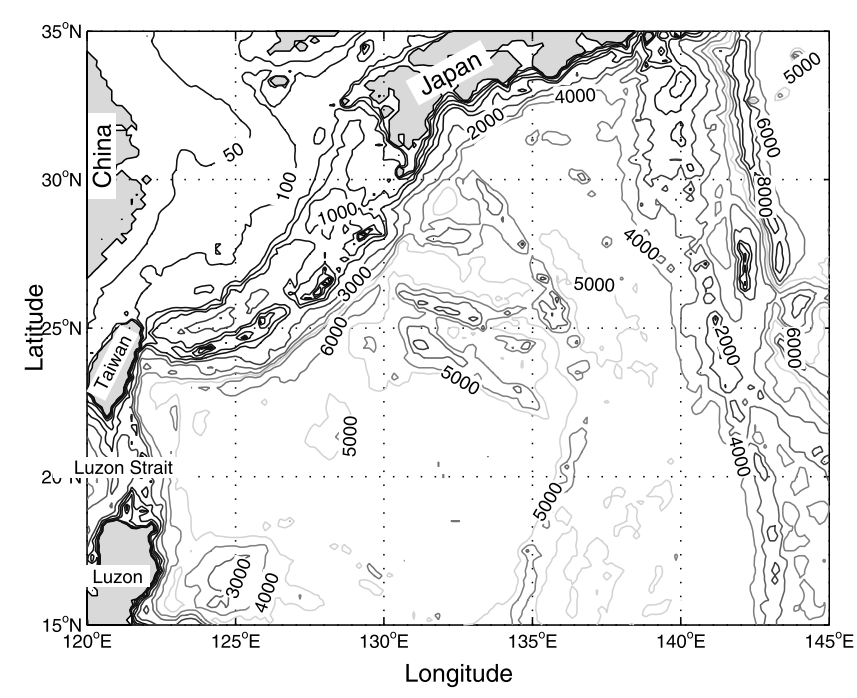

Figure 1. Geography and bottom topography of the Northwestern Pacific.

increment, $\Delta \sigma_{\theta}=0.025\left(\mathrm{~kg} \mathrm{~m}^{-3}\right)$. Thus, we have $222 \sigma_{\theta^{-}}$ layers. Within each layer, the density is vertically uniform. In order to well resolve isopycnal surfaces, we use cubic spline to interpolate the T, S data into 246 z-levels with three different increments: $5 \mathrm{~m}$ from 0 - to 100 -m depth, 10 $\mathrm{m}$ from 100 - to $1000-\mathrm{m}$ depths, $20 \mathrm{~m}$ from 1000 - to $2500-\mathrm{m}$ depths, and $50 \mathrm{~m}$ below $2500-\mathrm{m}$ depths. Thus, we build up a high-resolution data set $\left[T\left(z_{j}\right), S\left(z_{j}\right), \sigma_{\theta}\left(z_{j}\right)\right]$ in z-coordinate. Note that the value of 27.725 is the maximum value for $\sigma_{\theta}$, computed from the GDEM T, $\mathrm{S}$ data set.

\subsection{Transformation of $T, S$ Data from $z$-Coordinates to $\sigma_{\theta}$-Coordinate System}

[6] The z-coordinate potential density data $\hat{\sigma}_{\theta}\left(z_{j}\right)$ is compared to the discrete $\sigma$-values, $\sigma(\mathrm{k})$. The sigma value at the bottom of the k-th isopycnal layer, $\sigma^{b}(\mathrm{k})$, is used for the comparison,

$$
\sigma^{b}(k)=\frac{1}{2}[\sigma(k)+\sigma(k+1)]
$$

The depth for the bottom of the $\sigma(\mathrm{k})$-layer is obtained by

$$
\hat{z}_{k}^{(\sigma)}=z_{j}, \quad \text { if } \hat{\sigma}_{\theta}\left(z_{j}\right)=\sigma^{b}(k)
$$

and

$$
\hat{z}_{k}^{(\sigma)}=z_{j}+\frac{\sigma(k)-\hat{\sigma}_{\theta}\left(z_{j}\right)}{\hat{\sigma}_{\theta}\left(z_{j+1}\right)-\hat{\sigma}_{\theta}\left(z_{j}\right)}\left(z_{j+1}-z_{j}\right) \text { if } \hat{\sigma}_{\theta}\left(z_{j}\right)<\sigma^{b}(k)<\hat{\sigma}_{\theta}\left(z_{j+1}\right)
$$

where the superscript ' $b$ ' indicates the bottom of the k-th isopycnal layer. The thickness of the $\mathrm{k}$-th isopycnal layer is obtained by

$$
\hat{h}_{k}^{(\sigma)}=\hat{z}_{k-1}^{b}-\hat{z}_{k}^{b}
$$

\section{Velocity Vectors at Isopycnal Surface}

[7] After $\hat{h}_{k}{ }^{(\sigma)}$ is obtained, we may compute PV on the isopycnal surface, and then use the P-vector method to compute the absolute velocity [Chu and $L i, 2000$; Chu, 2000]. It is noticed that only the geostrophic velocity is obtained using the P-vector method [Chu, 1995]. Near the surface the geostrophic current is strong at least in the Kuroshio. Since the isopycnal $\sigma_{\theta}=23.5$ outcrops at $26^{\circ}$ $30^{\circ} \mathrm{N}$ (Figure 1)(Figure 2a), the isopycnal surface circulations near $\sigma_{\theta}=23.5$ might not be consistent with the direct measurements with current meters south of Honsu. Thus, the velocity at $\sigma_{\theta}=25.0$ is chosen to represent the Kuroshio Current and its extension near Honsu.

[8] Most important features from the computation are the westward flowing North Equatorial Current (NEC), the northeast flowing Kuroshio Current (KC) and the associated eddies and recirculation current from Kuroshio (RC), and the eastward flowing STCC. At $\sigma_{\theta}=23.5$, NEC is very weak.
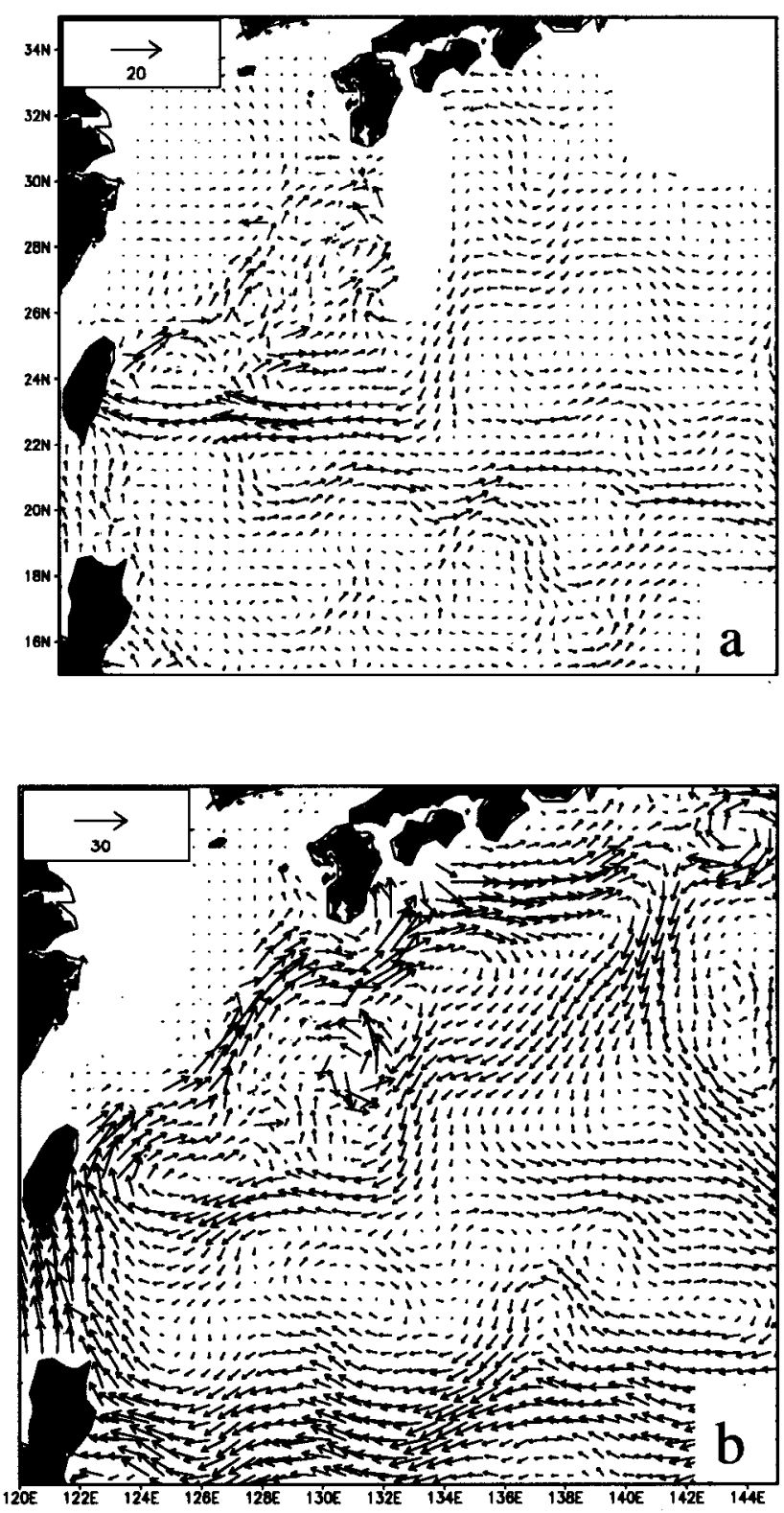

Figure 2. Absolute velocity vectors (unit: $\mathrm{cm} / \mathrm{s}$ ) in June on isopycnal surface (a) $\sigma_{\theta}=23.5$, and (b) $\sigma_{\theta}=25.0$. 

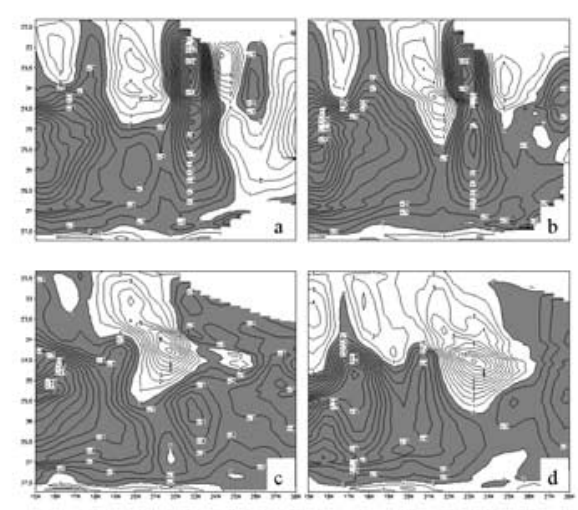

Figure 3. East-west absolute velocity (unit: $\mathrm{cm} / \mathrm{s}$ ) in June at meridional cross-sections: (a) $127.5^{\circ} \mathrm{E}$, (b) $129.5^{\circ} \mathrm{E}$, (c) $133.5^{\circ} \mathrm{E}$, and (d) $138.5^{\circ} \mathrm{E}$. Here, the shaded part (negative values) refers to the westward velocity.

The eastward flowing STCC originates mainly from the southward turning of RC (westward flowing) at (127$128^{\circ} \mathrm{E}, 23^{\circ} \mathrm{N}$ ). At $\sigma_{\theta}=25.0$ (Figure $2 \mathrm{~b}$ ), NEC is quite strong. Between $128^{\circ}-134^{\circ} \mathrm{E}$ a weak current flowing eastward along $21^{\circ} \mathrm{N}$ is the north flank of an anticyclonic eddy located at $18^{\circ}-21^{\circ} \mathrm{N}, 128^{\circ}-134^{\circ} \mathrm{E}$ (Figure 2b). Evident eastward flow (i.e., STCC) occurs east of $135^{\circ} \mathrm{E}$, which is different from STCC at $\sigma_{\theta}=23.5$. At deeper level $\left(\sigma_{\theta}=25.8\right)$, there is no eastward current in the subtropics (figure not shown).

[9] Two theories are available to explain the STCC formation: (a) the Ekman convergence [e.g., Roden, 1980] induced by westerlies to the north and trade winds to the south, and (b) the geostrophic convergence, which causes the midgyre front and its associated zonal current [Cushman-Roisin, 1984; Kubokawa, 1997]. Since the velocity is wholly determined by the density structure, the identification of STCC here tends to confirm the validity of the geostrophic convergence theory.

[10] Comparison between Figures $2 \mathrm{a}$ and $2 \mathrm{~b}$ shows a strong vertical shear in STCC. The baroclinic instability associated with the vertical shear causes STCC to meander between $19^{\circ}-25^{\circ} \mathrm{N}$ with the main axis at around $21.5^{\circ} \mathrm{N}$, and makes the eddy generation along it. STCC becomes wider with a maximum width of six degrees of latitude $\left(18^{\circ}-24^{\circ} \mathrm{N}\right)$ at $136^{\circ}-140^{\circ} \mathrm{E}$ as it flows eastward entraining water from eddies.

\section{Spatial Variability of STCC}

[11] The spatial variability of STCC is represented by four meridional cross-sections $\left(127.5^{\circ} \mathrm{E}, 129.5^{\circ} \mathrm{E}, 133.5^{\circ} \mathrm{E}\right.$, $\left.138.5^{\circ} \mathrm{E}\right)$ of the east-west absolute velocities on isopycnal surfaces (Figure 3). STCC is the eastward flow near the Tropics of Cancer $\left(23.5^{\circ} \mathrm{N}\right)$, and occurs in the upper layer above $\sigma_{\theta}=25.8$. The core of STCC is not located at the surface. The axis of STCC shifts northward as $\sigma_{\theta}$ increases, and the speed of STCC increases eastward. For example, the maximum velocity of STCC is around $4 \mathrm{~cm} \mathrm{~s}^{-1}$ near $20^{\circ} \mathrm{N}$ between $\sigma_{\theta}=23.0$ and $\sigma_{\theta}=24.0$ at $127.5^{\circ} \mathrm{E}$ crosssection (Figure 3a), greater than $6 \mathrm{~cm} \mathrm{~s}^{-1}$ near $21^{\circ} \mathrm{N}$ and $\sigma_{\theta}=24.2$ at $129.5^{\circ} \mathrm{E}$ cross-section (Figure $3 \mathrm{~b}$ ), greater than $9 \mathrm{~cm} \mathrm{~s}^{-1}$ near $21.5^{\circ} \mathrm{N}$ and $\sigma_{\theta}=24.3$ at $133.5^{\circ} \mathrm{E}$ cross- section (Figure $3 \mathrm{c}$ ), and greater than $12 \mathrm{~cm} \mathrm{~s}^{-1}$ near $23^{\circ} \mathrm{N}$ and $\sigma_{\theta}=24.5$ at $138.5^{\circ} \mathrm{E}$ cross-section (Figure $3 \mathrm{~d}$ ). At the $\sigma_{\theta}$ level where the core of STCC located, the speed of STCC is usually higher than the speed of NEC. This is because the core of NEC is located at deeper layers. The volume transport of STCC at $138.5^{\circ} \mathrm{E}$ is estimated as $8 \mathrm{SV}$ $\left(1 \mathrm{~Sv}=10^{6} \mathrm{~m}^{3} \mathrm{~s}^{-1}\right)$.

\section{Potential Vorticity}

[12] STCC mainly comes from southward turning of the recirculation current from Kuroshio (i.e. RC), which originates at southern latitudes $\left(\sim 15^{\circ} \mathrm{N}\right)$ where PV is relatively low. Scale analysis shows that the dissipative force alone is not sufficient to remove the low PV anomalies [Pedlosky, 1987] for a narrow boundary current such as KC and RC. Talley [1988] pointed out the existence of a minimum PV area corresponding to the subtropical mode water located at $\sigma_{\theta}=25.4$ level in the western Pacific. The minimum PV enclosed by $25 \times 10^{-10} \mathrm{~cm}^{-1} \mathrm{~s}^{-1}$ at the cross-section of $138.5^{\circ} \mathrm{E}$ (Figure $4 \mathrm{~b}$ ) indicates the location of the subtropical mode water. The STCC core is located above the southern boundary of the subtropical mode water (i.e., minimum PV) from the comparison between Figures $3 \mathrm{~d}$ and 4 . This result consists with the recent modeling studies [e.g., Kubokawa, 1997].

\section{Conclusions}

[13] The goal of this study is to investigate the spatial variability of summer Subtropical Countercurrent on isopycnal surfaces in the northwestern Pacific using the Navy's unclassified GDEM data on $0.5^{\circ} \times 0.5^{\circ}$ resolution. We use the P-vector inverse method for determining the absolute geostrophic velocity on the isopycnal surface. The results are summarized as follows.

1. The eastward currents at upper levels (above $\sigma_{\theta}=$ 24.5) reveal multi-core structure. STCC is located at $19^{\circ}-$

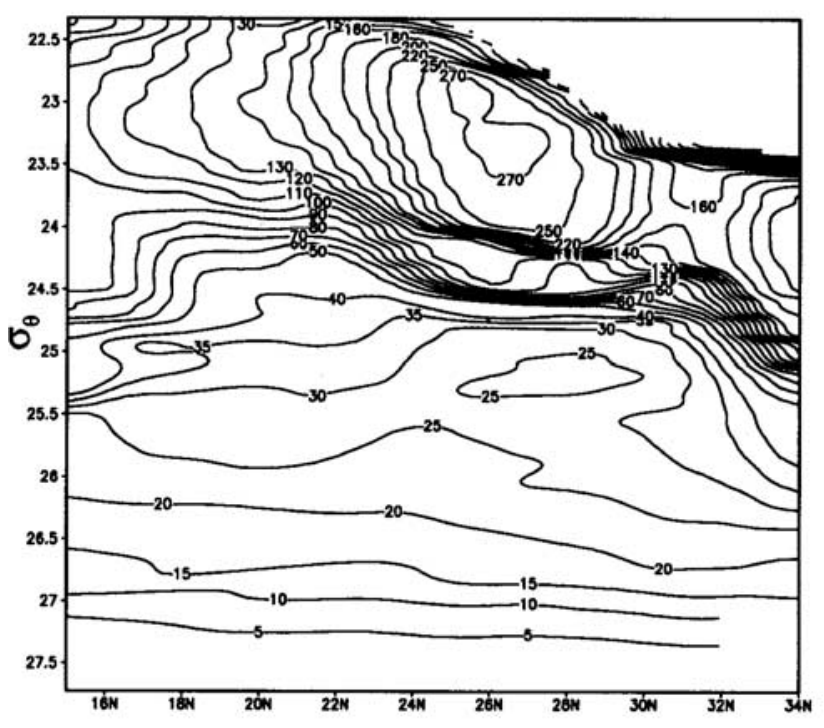

Figure 4. Meridional cross-section $\left(138.5^{\circ} \mathrm{E}\right)$ of June potential vorticity (in $10^{-10} \mathrm{~cm}^{-1} \mathrm{~s}^{-1}$ ). 
$23^{\circ} \mathrm{N}$. Eastward flow segments occurring south of $17^{\circ} \mathrm{N}$ are usually the southern flanks of local cyclonic eddies rather than a part of a continuous current. Below the level of $\sigma_{\theta}=$ 24.5, STCC has a single core located $19^{\circ}-23^{\circ} \mathrm{N}$ west of $134^{\circ} \mathrm{E}$ and $22^{\circ}-26^{\circ} \mathrm{N}$ east of $134^{\circ} \mathrm{E}$.

2. STCC originates at $122.5^{\circ} \mathrm{E}$ at $\sigma_{\theta}=23.5$. As $\sigma_{\theta}$ increases, the origin of STCC shifts eastward. The major source of STCC is the southeastward turning of the recirculation current from Kuroshio. STCC strengthens and broadens as it flows eastward. The volume transport of $\mathrm{STCC}$ at $138.5^{\circ} \mathrm{E}$ is estimated as $8 \mathrm{~Sv}\left(1 \mathrm{~Sv}=10^{6} \mathrm{~m}^{3} \mathrm{~s}^{-1}\right)$.

3. The STCC core is not located at the surface, but the layer between $\sigma_{\theta}=23.0$ and $\sigma_{\theta}=24.7$, where STCC is stronger than NEC. Moreover, STCC core is above the southern boundary of the subtropical mode water.

4. STCC disappears below the level of $\sigma_{\theta}=25.8$, that is to say, STCC is an upper ocean current. Its maximum depth is around $300 \mathrm{~m}$.

[14] Acknowledgments. Peter Chu was supported by the Office of Naval Research and the Naval Oceanographic Office. Rongfeng Li and Xiaobao You were supported by the Chinese National Science Foundation (40076009), and Chinese Academy of Sciences (KZCX2-204, KZCX1SW-01-16).

\section{References}

Chu, P. C., P-vector method for determining absolute velocity from hydrographic data, Marine Tech. Soc. J., 29(2), 3-14, 1995.

Chu, P. C., P-vector spirals and determination of absolute velocities, J. Oceanogr., 56, 591-599, 2000.
Chu, P. C., and R. F. Li, South China Sea Isopycnal-Surface circulation, J. Phys. Oceanogr., 30, 2419-2438, 2000.

Cushman-Roisin, B., On the maintenance of the Subtropical Front and its associated countercurrent, J. Phys. Oceanogr., 14, 1179-1190, 1984

Kubokawa, A., A two-level model of subtropical grye and subtropoical countercurrent, J. Oceanogr., 53, 231-244, 1997.

Pedlosky, J., Geophysical Fluid Dynamics, Springer-Verlag, 710 pp., 1987.

Qiu, B., Seasonal eddy field modulation of the North Pacific Subtropical Countercurrent: TOPEX/Poseidon observations and theory, J. Phys. Oceanogr., 29, 2471-2486, 1999.

Roden, G. L., On the variability of surface temperature fronts in the western Pacific, as detected by satellite, J. Geophys. Res., 85, 2704-2710, 1980.

Talley, L. D., Potential vorticity distribution in the North Pacific, J. Phys. Oceanogr., 18, 89-106, 1988.

Teague, W. J., M. J. Carron, and P. J. Hogan, A comparison between the Generalized Digital Environmental Model and Levitus climatologies, J. Geophys. Res., 95, 7167-7183, 1990.

Uda, M., On the Subtropical Convergence and the currents in the Northwestern Pacific, Rec. Oceanogr. Works. Japan, 2, 141-150, 1955.

Uda, M., and K. Hasunuma, The eastward Subtropical Countercurrent in the western North Pacific Ocean, J. Oceanogr. Soc. Japan, 25, 201-210, 1969.

White, W., K. Hasunuma, and H. Solomon, Large-scale season and secular variability of the Subtropical Front in the western North Pacific from 1954 to 1974, J. Geophys. Res., 83, 4531-4544, 1978.

Yoshida, K., and T. Kidokoro, A Subtropical Countercurrent in the North Pacific-An eastward flow near the Subtropical Convergence, J. Oceanogr. Soc. Japan, 23, 88-91, 1967a.

Yoshida, K., and T. Kidokoro, A Subtropical Countercurrent (II)-A prediction of eastward flows at lower subtropical latitudes, J. Oceanogr. Soc. Japan, 23, 231-246, 1967b.

P. C. Chu, Department of Oceanography, Naval Postgraduate School, Monterey, CA 93943, USA.

R. Li and X. You, LASG, Institute of Atmospheric Physics, Chinese Academy of Sciences, Beijing, China. 